\title{
On Hierarchical Syndrome Analysis and the Zürich-Montpellier
}

\section{Table Method}

\author{
B. J. COETZEE* and M. J. A. WERGER*
}

\section{ABSTRACT}

Hierarchical Syndrome Analysis was applied to two sets of data drawn from Werger, et al. (1972). The resulting classification was compared to that obtained by Werger et al., who used the ZürichMontpellier Table Method. It is concluded that Hierarchical Syndrome Analysis results in an advanced stage of the process that leads to a meaningful classification of vegetation as expressed in a phytosociological table obtained by Zürich-Montpellier techniques. However, the Hierarchical Syndrome Analysis was found to be too rigid in some respects to finalize such a classification. The time and effort involved in preparing the data for computation is another serious consideration. The main conclusion is that the consistency of the results of the Hierarchical Sydrome Analysis with those obtained by the Zürich-Montpellier Table Method, proves the objectivity of the latter.

\section{INTRODUCTION}

The once seemingly unbridgeable gap in phytosociology between the schools using statistical techniques and the Zürich-Montpellier School with its so-called subjective methods, has been reduced in recent years by various studies that compared the results of both types of methods. Some of these studies dealt with a comparison of efficiency of these types of methods (e.g. Van Groenewoud, 1965; Ivimey-Cook \& Proctor, 1966; Moore, et al., 1970), whereas in others the application of a method of one type was initiated as an aid towards the interpretation of results obtained with a method of the other type (e.g. Van der Maarel, 1969; Coetzee, 1972; Werger, 1972). The results of a wide range of statistical methods, such as association analysis, inverse analysis, weighted pair group method of cluster analysis using different coefficients of similarity, principal component analysis, and others, were compared in this way with those obtained by the table method of the Zürich-Montpellier School As stated recently by Goodall (1970), none of these available statistical methods for clustering samples of vegetation has yet established itself as consistently preferable, and variety might be advantageous in the present stage of development of this methodology, since this variety might add new facets to the description of the acquired clusters and their interrelationships.

One of the methods of clustering that, as far as we know, was never used on vegetation data, is Hierarchical Syndrome Analysis as introduced by McQuitty (1960). It is a relatively simple polythetic, agglomerative method, that has proven its merit in an analysis of climatological data (Welding, pers. comm.).

In this study Hierarchical Syndrome Analysis was applied to two sets of data taken from Werger, et al. (1972), in an attempt to determine the value of this method in the analysis of vegetation data. The first set of data comprises eight stands of relatively simple scrub and forest vegetation, whereas the second

* Botanical Research Institute, Department of Agricultural Technical Services, Private Bag X101, Pretoria. set comprises 36 stands of floristically rich Fynbos vegetation, both from Swartboschkloof near Stellenbosch in the South-western Cape Province.

These data were synthesized and interpreted by Werger, et al. (1972) by means of the Zürich-Montpellier Table Method. This facilitated the interpretation of the results of the Hierarchical Syndrome Analysis and allowed a comparison thereof with the results of the Zürich-Montpellier Table Method.

\section{METHODS}

The method is used to group individuals (entities) into classes of successively lower levels of similarity, or into a "hierarchical system of syndromes", so that on the highest level every entity in a class is more like every other entity in that class than it is like any entity in any other class (McQuitty, 1960). At each following stage of synthesis an established class is regarded as one synthetic individual (entity). The similarity between a class and an individual, or between two classes, is taken as the lowest correlation between a member of that class and the single individual or pair of individuals, one from each class. This is because it is assumed that the members of a class have as much in common as the pair of members with the lowest similarity. However, this assumption need not be absolutely valid; the only requirement is that valid classes have higher estimates for overall similarity than competing ones (McQuitty, 1960). McQuitty actually found that the assumption invariably over-estimated the scores for overall similarity, but nevertheless resulted in satisfactory classifications as compared with those obtained by more elaborate methods. Of the two versions described by McQuitty, the one adopted here is the "replacement version".

In this study correlations were calculated with the product-moment correlation coefficient, reported to give the best results in a cluster analysis carried out by Moore, et al. (1970).

For each set of data two analyses were carried out, one to group the stands and one to group the species. 
For purpose of calculation cover-abundance figures were transformed as follows:

$\begin{array}{rrrrrrr}r & + & 1 & 2 & 3 & 4 & 5 \\ 1 & 5 & 10 & 20 & 30 & 40 & 50\end{array}$

This was adopted after a number of trials which included the transformation of cover-abundance values proposed by Moore, et al. (1970) and which was felt to underestimate especially the lower values, + and 1 , of the scale.

The analysis was carried out using all eight stands and all 74 species, i.e. all species occurring in Table 2 and Appendix 2 of Werger, et al. (1972), in the case of the first set of data, whereas all 36 stands and only the 147 species occurring in Table 1 of Werger, et al. (1972) were used for the second set of data. The Zürich-Montpellier Table Method was already discussed by Werger, et al. (1972).

\section{RESULTS}

The results of the analysis of the eight stands of scrub and forest vegetation are represented in Fig. $\mathrm{la}$ and $\mathrm{lb}$. Fig. Ia shows three main legs of the dendrogram, corresponding to the three communities recognized by Werger, et al. (1972: Table 2). It confirms that the two forest communities, the Rapanea melanophloeos Community and the Heeria argentea Community, are more similar to each other than any of them to the Brabeium stellatifolium Riverinescrub Community.

In the classification of species of the first set of data, as shown by Fig. Ib, one main leg includes all species characteristic of the Brabeium stellatifolium Community, as well as the Fynbos species intruding into this community. This leg also includes a number of species occurring only once and in a stand of the Brabeium stellatifolium Community. Two species of general occurrence over this set of data, Restio subverticillatus and Chironia baccifera, and three species common to this and the Rapanea melanophloeos Community, Cunonia capensis, Brachylaena neriifolia and Oplismenus hirtellus, all reaching relatively high cover-abundance values in the Brabeium stellatifolium Community, are also included in this leg of the dendrogram.

A second main leg includes all species characteristic of the Rapanea melanophloeos Community and three species common to this community and the Heeria argentea Community, Olea africana, Maytenus acuminatus and Halleria lucida, that reach

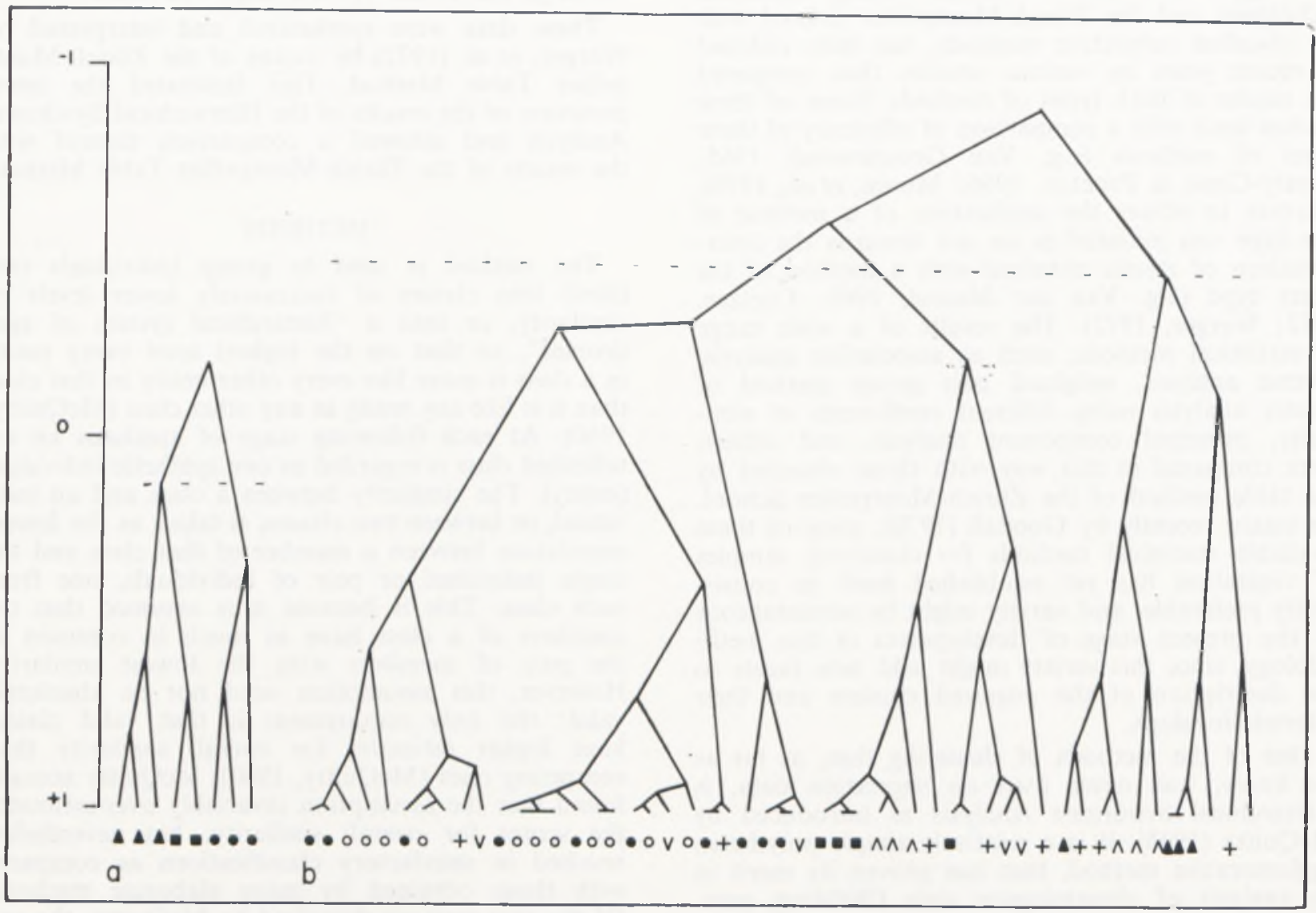

Fig. 1. Classification of scrub and forest vegetation. Explanation in text.

a. Classification of stands. Heeria argentea Community; Rapanea melanophloeos Community; Braheium stellarifolium Community.

r Classification of species. Character species of Brabeium stellatifolium Community; species intruding in Brabeium stellatifolium Community; + species common to Brabeium stellatifolium, Rapanea melanophloeos and Heeria argentea Communities; $V$ species common to Brabeium stellatifolium and Rapanea melanophloeos Communities; - character species of Rapanea melanophloeos Community; $\wedge$ species common to Rapanea melanophloeos and Heeria argentea Communities; $\boldsymbol{\Delta}$ character species of Heeria argentea Community. Species occurring only once and in the same stand are correlated at level + 1 and represented in the dendrogram by one ending. No symbol is assigned to these and other species occurring only once. 
relatively high cover-abundance values in the Rapanea melanophloeos Community. This leg further includes two species common to the Rapanea melanophloeos and the Brabeium stellatifolium Communities, Asparagus scandens and Ilex mitis, three species of general occurrence, Blechnum punctulatum, Myrsine africana and Knowltonia capensis, and three species of single occurrence.

The third main leg of the dendrogram includes all species characteristic of the Heeria argentea Community, as well as the three remaining species common to this and the Rapanea melanophloeos Community. Three species of general occurrence, Maytenus oleoides, Secamone alpini and Hartogia schinoides, of which the latter two constantly reach higher cover-abundance values within this community, are also grouped in this main leg, together with four species of single occurrence.

Fig. 2a shows the grouping of the 36 stands of complex Fynbos vegetation into four main "syndromes", which correspond closely to the communities recognized by Werger et al. (1972: Table 1). One main leg comprises all four stands of the Berzelia lanuginosa-Osmitopsis asteriscoides Community.

A second main leg combines all stands of the Protea arborea-Rhus angustifolia community with the two typical stands of the Restio perplexus community. The affinity between these two communities was already emphasized by Werger, et al. (1972). The originally unclassified stand 22 , as well as stand
7 of the Brunia nodiflora-Psoralea rotundifolia Community and stand 21 of the Thamnochortus gracilis-Hypodiscus aristatis Community are also grouped in this main leg. This classification of stands 7 and 21 may be due to some exceptional cover-abundance values scored by species in these stands, for example by Protea neriifolia, which is otherwise of particular importance in the Protea arborea-Rhus angustifolia Community.

A third main leg is composed of stands of the Thamnochortus gracilis-Hypodiscus aristatus Community. Stand 34, which was originally described as transitional between this and the Restio perplexus Community, is also included in this group. Stands 27 and 29 of this Community, that were originally pointed out as not fully representative, are not included in this main leg. but in the fourth one, that combines the stands of the Brunia nodiflora Psoralea rotundifolia communities, except for stand 7 as pointed out already. Regarding the species classification of the Fynbos stands (Fig. 2b), it should be noted that species labelled by Werger, et al. (1972) as accompanying species, are generally those that occur too infrequently to be included into another group of the table. In the Hierarchical Syndrome Analysis these species, were necessarily classified on the basis of their distribution and coverabundance scores, despite their infrequent occurrences. Thus their occurrence in any group will be regarded as insignificant, and will not be further commented upon.

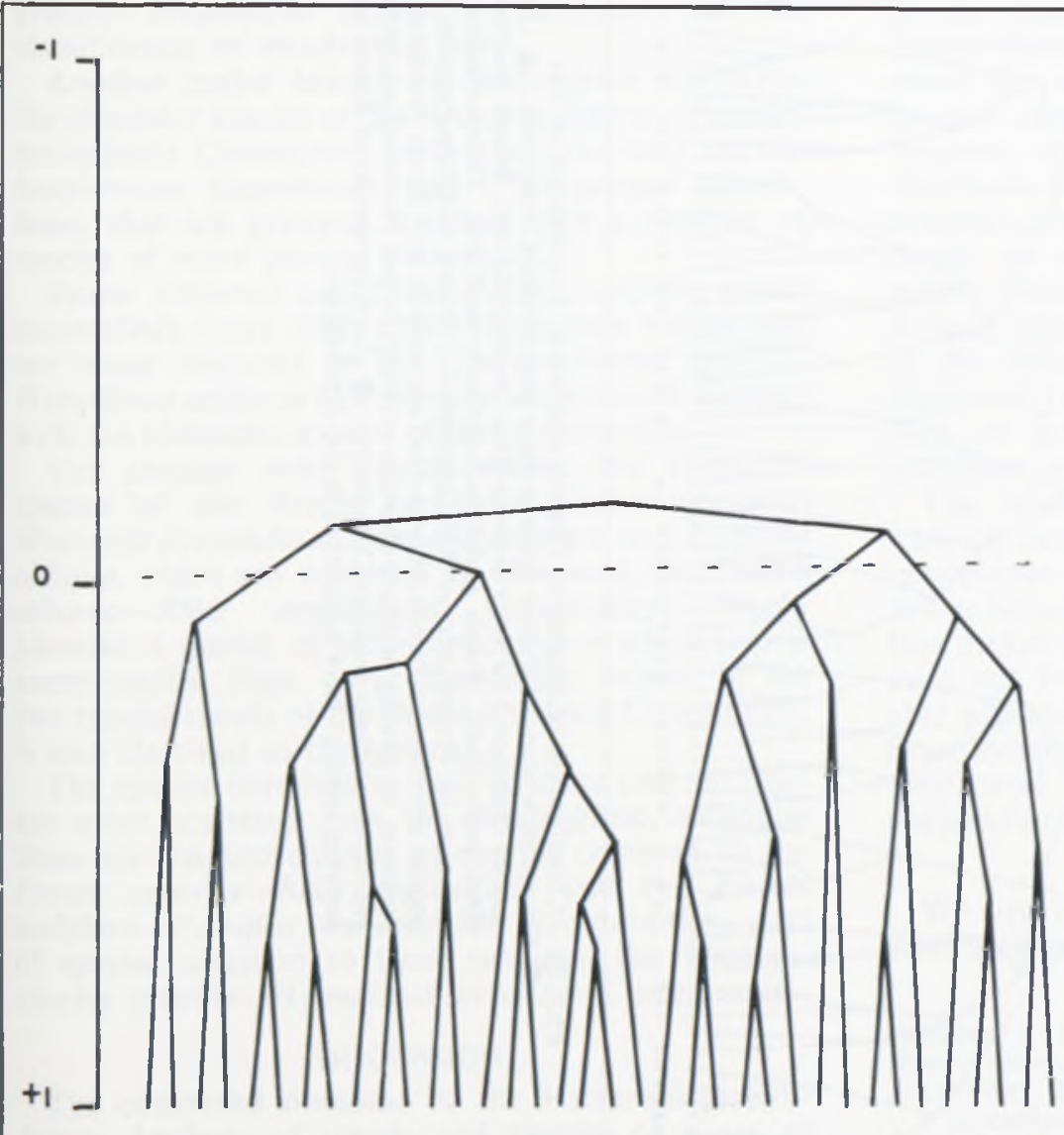

FIG. 2a.-Classification of stands of Fynbos vegetation. Explanation in text.

- Berzelia lanuginosa-Osmitopsis asreriscoides Community; $\bigcirc$ Restio perplexus Community; Protea arborea-Rhus angustifolia Community; Thamnochortus gracilisHypodiscus aristatus Community; - Brunia nodiflora-Psoralea rotundifolia Community. 

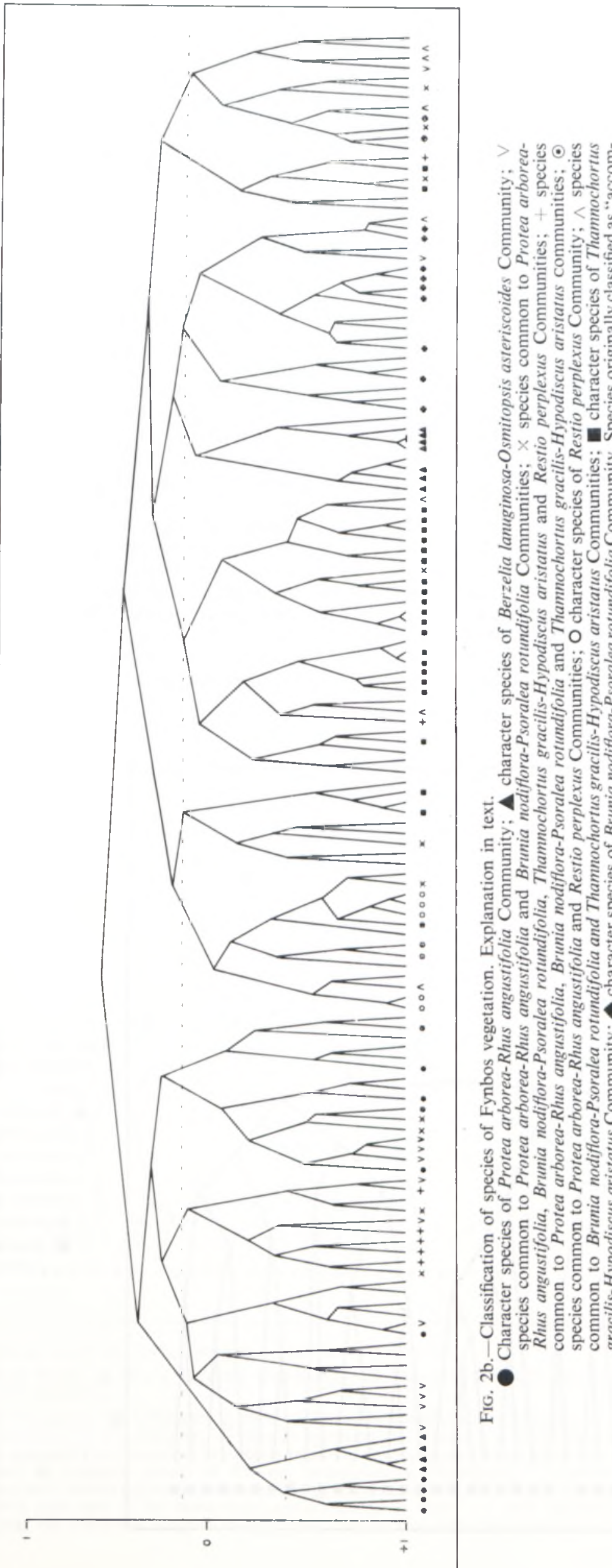

cin

焉.

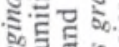

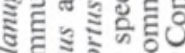

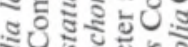

จ

จํํㅇํำ

o

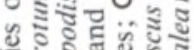

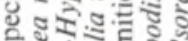

4

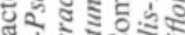

政

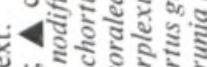
\. 틀

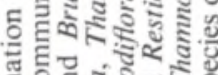

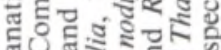

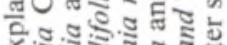

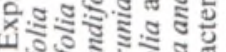
6 जั है 急

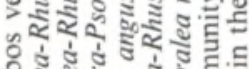

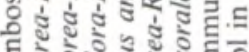

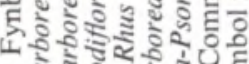
ह

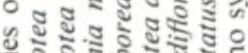

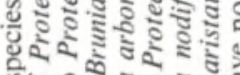

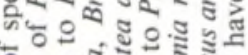

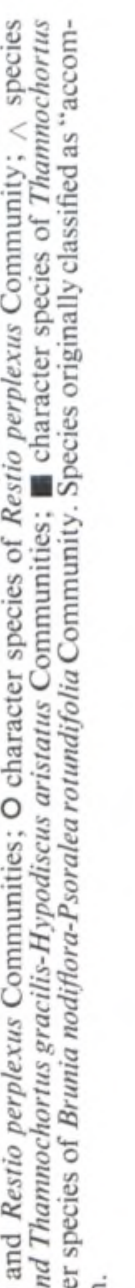

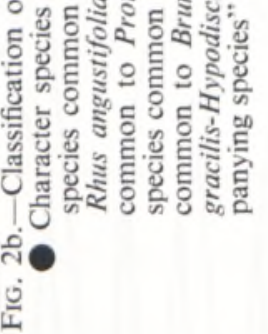


One leg of the dendrogram consists of the character species Diospyros glabra, Rhus angustifolia, Cassvtha ciliolata and Pteridium aquilinum of the Protea arborea-Rhus angustifolia Community, that also intrude into the Berzelia lanuginosa-Osmitopsis asteriscoides Community.

The remaining character species of this community, which only score low cover-abundance values, are spread over the dendrogram.

Two main legs of the dendrogram comprise the character species of the Berzelia lanuginosa-OSmitopsis asteriscoides Community. The separation of these species over two legs may be due to an unevenness of cover-abundance scorings of these species in the stands of this community.

Another main leg is composed of most of the character species of the Thamnochortus gracilisHypodiscus aristatus Community plus four species of less restricted occurrence, Aristea capitata, Pentaschistis steudelii, Metalasia muricata and Erica hispidula of which the latter two tend to have higher frequencies and/or higher cover-abundance values within this community.

Two of the character species of this community, Blaeria dumosa and Pentameris macrocalycina, which both reach relatively high cover-abundance values in stand 14, appear together in a separate leg. Two other character species, Restio sieberi and Coleonema juniperinum are also classified away from the main group of character species, and form a leg together with Pentaschistus colorata and Cliffortia ruscifolia. These four species score exceptionally high coverabundance values in stand 27 , which was also separated from the other stands of the Thamnochortus gracilis-Hypodiscus aristatus Community in the classification of stands (Fig. 2a).

Another major branch of dendrogram comprises the character species of the Brunia nodiflora-Psoralea rotundifolia Community, with the exception of Osteospermum tomentosum and Elytropappus glandulosus, that are grouped together with a number of species of more general occurrence.

Restio filiformis and Pentaschistus curvifolia, which respectively score high cover-abundance values and are more frequent in the Thamnochortus gracilisHypodiscus aristatus Community, are grouped together with the character species of this community.

Yet another main leg combines the character species of the Restio perplexus Community with Watsonia pyramidata, Themeda triandra and Psoralea obliqua, which are common to this and the Protea arborea-Rhus angustifolia Community. Stoebe plumosa, a species of general occurrence which scored exceptionally high cover-abundance values in the two typical stands of the Restio perplexus Community, is also classified in this group.

The species common to two or more communities are more scattered over the dendrogram, although there are marked clusters of species common to the Protea arborea-Rhus angustifolia and the Brunia nodiflora-Psoralea rotundifolia Communities, and of species common to these two and the Thamnochortus gracilis-Hypodiscus aristatus Communities.

\section{DISCUSSION}

The combined outcome of the Hierarchical Syndrome Analysis of stands and species of a set of data lead to a result that is largely consistent with a meaningfully interpreted classification of vegetation.
Possibly still better results might be obtained by slightly changing the general transformation of cover-abundance values and introducing a scale of degree of absence similar to the one proposed by Swan (1970). This means that Hierarchical Syndrome Analysis can be a useful tool in the construction of an advanced stage of a meaningful classification of vegetation as is expressed in a phytosociological table obtained by Zürich-Montpellier techniques. However, in estimating the value of Hierarchical Syndrome Analysis two things should be borne in mind. Firstly, the result of a Hierarchical Syndrome Analysis cannot be regarded as a completed analysis of vegetation data, because the procedure rigidly classifies stands and species. Some subtle decisions based on more complex criteria than correlation coefficients only have to be taken in order to arrive at a correct, meaningful placing of certain stands and species. For example, particular values for a certain attribute should not always be given the same weight, but the general pattern of occurrence of a species in the data should in some cases be permitted to affect the weighting of cover-abundance values. Thus, the weight of the score of 2 of Restio subverticillatus in stand 31 must have been the cause for its placing in the group of character species of the Brabeium stellatifolium Community (Fig. lb), whereas its general distribution pattern (Werger, et al. 1972: Table 2) shows that it is not at all typical for that community. Secondly, the time and effort involved in preparing the data for computation should not be underestimated.

Perhaps the most important conclusion drawn from this study is that the similarity of the results of the Hierarchical Syndrome Anylysis and the Zürich-Montpellier Table Method contributed to prove the often doubted objectivity of the latter. In this sense the present study showed that the "amount of art" involved in constructing a ZürichMontpellier phytosociological table is largely "unreconstructed logic-in-use" and thus it helped to clarify the theoretical significance of Zürich-Montpellier phytosociological procedures (Hull, 1970). Already Ellenberg (1956) had stressed the objectivity of the table method and the success of Spatz \& Siegmund (1972), who used the same data as Ellenberg, in arriving at a virtually identical result by computer processing, further illustrated this point.

The often heard arguments that the subjective way of sampling or the assignment of estimated importance values to species in the Zürich-Montpellier School already introduces a subjective element, that makes it impossible to obtain an objective result, need not be important, since meaningful interpretable phytosociological tables can also be constructed from systematically distributed samples (e.g. Taylor, 1969) and where measured importance values are assigned to species.

\section{ACKNOWLEDGEMENT}

We are indebted to $\mathrm{Mr} \mathrm{M}$. C. Welding for his kind assistance with the computations.

\section{REFERENCES}

Coetzee, B. J., 1972. 'n Plantsosiologiese studie van die Jack Scott-Natuurreservaat. Unpubl. M.Sc. Thesis, Univ. Pretoria. EllenberG, H, 1956. Aufgaben und Methoden der Vegetationskunde. in H. Walter: Einführung in die Phytologie. Bd. 4. T. 1. Stuttgart: Ulmer.

Goodall, D. W., 1970. Statistical plant ecology. Ann. Rev. Ecol. Syst. 1:99-124. 
Hull, D. L., 1970. Contemporary systematic philosophies. Ann. Rev. Ecol. Syst. 1: 19-54.

Ivimey-COOK, R. B. \& Procror, M. C. F., 1966. The application of association-analysis to phytosociology. J. Ecol. 54: 179-192.

MCQuirry, L. L., 1960. Hierarchical Syndrome Analysis. Educ. Psychol. Meas. 20: 293-304.

Moore, J. J., Fitzsimons, P., Lambe, E. \& White, J., 1970. A comparison and evaluation of some phytosociological techniques. Vegetatio 20: 1-20.

Spatz, G. \& Siegmund, J., 1972. Eine Methode zur tabellarischen Ordination, Klassifikation und ökologischen Auswertung von pflanzensoziologischen Bestandsaufnahmen durch den Computer. Vegetatio, in the press.

SWAN, J. M. A., 1970. An examination of some ordination problems by use of simulated vegetation data. Ecology 51: $89-102$
TAYLOR, H. C., 1969. A vegetation sirvey of the Cape of Good Hope Nature Reserve. Unpubl. M.Sc. thesis, Univ. Cape Town.

VAN DER MAAREL, E., 1969. On the use of ordination models in phytosociology. Vegetatio 19: 21-46.

Van Groenewoud, H., 1965. Ordination and classification of Swiss and Canadian coniferous forests by various biometric and other methods. Ber. Geobot. Inst. ETH, Stiftung Rübel 36: $2-102$.

WERGER, M. J. A., 1972. On the use of association-analysis and principal component analysis in interpreting a BraunBlanquet phytosociological table of a Dutch grassland. Vegetatio: in the press.

Werger, M. J. A., Kruger, F. J. \& Taylor, H. C., 1972. A phytosociological study of the Cape Fynbos and other vegetation at Jonkershoek, Stellenbosch. Bothalia 10 : 599-614, also as: Pflanzensoziologische Studie der Fynbos Vegetation am Kap der Guten Hoffnung. Vegetatio 24 71-89. 